\title{
Identification of the Parameters of the Instantaneous Point Pollution Source in the Azov Sea Based on the Adjoint Method
}

\author{
V.S. Kochergin*, S.V. Kochergin \\ Marine Hydrophysical Institute, Russian Academy of Sciences, Sevastopol, Russian Federation \\ *e-mail:vskocher@gmail.com
}

\begin{abstract}
The passive admixture transport model in the Azov Sea is considered. The problem of cartelistic impulse local source identification at the sea surface based on adjoint method is solving by integration of independent series of adjoint tasks. Simultaneous solution of this problem at the parallel mode is realized by the aforementioned approach. The efficiency of the algorithm optimal value power of source search agreed with the data measurements is shown in the test example. The measurement data assimilation algorithm in the passive admixture transfer model is implemented applying variational methods of filtration for optimal estimate retrieval. The retrieval is carried out by means of the method of adjoint equations and solving of linear systems. On the basis of the variational filtration method of data assimilation, the optimal estimate retrieval algorithm for pollution source power identification is constructed. In application of the algorithm, the integration of the main, linked and adjoint problems is implemented. Integration problems are solved using TVD approximations. For the application of the procedure, the Azov current fields and turbulent diffusion coefficients are obtained using the sigma coordinate ocean model (POM) under the eastern wind stress conditions being dominant at the observed time period. Furthermore, the results can be used to perform numerical data assimilation on loads of suspended matter.
\end{abstract}

Keywords: power source identification, concentration field, assimilation of measurement data, admixture transport, adjoint problem, the Azov Sea.

DOI: 10.22449/1573-160X-2017-1-62-67

(C) 2017, V.S. Kochergin, S.V. Kochergin

(C) 2017, Physical Oceanography

Introduction. The increasing anthropogenic impact on the Azov Sea water area requires the creation of environmental condition monitoring systems, allowing the operative assessment of the environmental situation in areas exposed to human impact, especially in heavy traffic and port areas. Solution of these problems is possible on the basis of methods of mathematical modeling of passive admixture transport [1] and methods for solving inverse problems [2 - 4], where the identification of certain numerical simulation parameters are based on measurements due to their assimilation. Recently, the variational assimilation methods and the adjoint method are actively developed and used to handle the oceanographic problems [5 - 7]. To provide timely information about the studied object condition numerical implementation of these models and algorithms should be realized on high-performance computers applying with the up-to-date approaches, including parallelization. The algorithms of measurement data assimilation are generally based on the minimization of a quadratic functional quality that characterizes the deviation of the model solutions from the measurement data. At that, the model of passive admixture transport acts as limitations on the variations of the input parameters. In [8] a variational algorithm for the power source identification is considered. In this paper, the adjoint method [9] is applied. It gives a possibility of the efficient (in terms of computing process organization) search for pollution source parameters. 
The adjoint method. Below the model of passive admixture transport in $\sigma$ coordinates is considered

$$
\frac{\partial D C}{\partial t}+\frac{\partial D U C}{\partial x}+\frac{\partial D V C}{\partial y}+\frac{\partial W C}{\partial \sigma}=\frac{\partial}{\partial x} A_{H} \frac{\partial D C}{\partial x}+\frac{\partial}{\partial y} A_{H} \frac{\partial D C}{\partial y}+\frac{\partial}{\partial \sigma} \frac{K}{D} \frac{\partial C}{\partial \sigma}
$$

with the following conditions on the side boundaries

$$
\Gamma: \frac{\partial C}{\partial n}=0
$$

the boundary conditions on the surface and at the bottom

$$
\begin{aligned}
& \sigma=0: \frac{\partial C}{\partial \sigma}=Q, Q=Q_{S} \cdot \delta(t-0) \cdot \delta\left(x-x_{0}\right) \cdot \delta\left(y-y_{0}\right), \\
& \sigma=-1: \frac{\partial C}{\partial \sigma}=0
\end{aligned}
$$

and the initial data as follows

$$
C(x, y, \sigma, 0)=0
$$

where $t$ is the time; $x_{0}, y_{0}$ are the point source coordinates; $D$ is the dynamic depth; $C$ is the admixture concentration; $Q$ is the instant point source with the power $Q_{S} ; U, V, W$ are the velocity field components; $A_{H}$ and $K$ are horizontal and vertical diffusion components correspondingly; $n$ is the normal to the side boundary.

Multiplying the expressions (1) - (4) on $C^{*}$ and integrating by parts, taking into account the boundary conditions and the adjoint equation analog to the $\sigma$ coordinates

$$
\frac{\partial D}{\partial t}+\frac{\partial D U}{\partial x}+\frac{\partial D V}{\partial y}+\frac{\partial W}{\partial \sigma}=0
$$

choosing $C^{*}$ to be a solution of the following adjoint problem:

$$
\begin{gathered}
-\frac{\partial D C^{*}}{\partial t}-\frac{\partial D U C^{*}}{\partial x}-\frac{\partial D V C^{*}}{\partial y}-\frac{\partial W C^{*}}{\partial \sigma}- \\
-D \frac{\partial}{\partial x} A_{H} \frac{\partial C^{*}}{\partial x}-D \frac{\partial}{\partial y} A_{H} \frac{\partial C^{*}}{\partial y}-\frac{\partial}{\partial \sigma} \frac{K}{D} \frac{\partial C^{*}}{\partial \sigma}=0, \\
\Gamma: \frac{\partial C^{*}}{\partial n}=0, \sigma=0: \frac{\partial C^{*}}{\partial \sigma}=g, \sigma=-1: \frac{\partial C^{*}}{\partial \sigma}=0, \\
t=T: C^{*}=0,
\end{gathered}
$$

we'll obtain

$$
\int_{S} Q \cdot C^{*} \cdot d S=\int_{S} C \cdot g \cdot d S,
$$


where $S$ is the sea surface; $g=\delta(t-T) \cdot \delta\left(x-x_{n}\right) \cdot \delta\left(y-y_{n}\right), n=1, \ldots, N, N-$ is the total number of measuring points for the final time. Taking into account the representations for $Q$ and $g$ from the formula (9), we have

$$
Q_{S} C_{n}^{*}\left(0, x_{0}, y_{0}, 0\right)=C\left(T, x_{n}, y_{n}, 0\right), n=1, \ldots, N .
$$

The formula (9) is similar to the formula obtained in the method of concentration field assessment [10] for different initial conditions, and is inherently a dual representation [9] of concentration through the power and the relevant adjoint problem solution. Note that $N$ of the adjoint problems for $N$ points are independent from each other and may be implemented in parallel by different executors (processors).

In case the emission point coordinates $\left(x_{0}, y_{0}\right)$ are to be determined, then solving $N$ of the adjoint problems (6) - (8), it is possible to define the area $\Omega=\bigcap L_{n}, n=1, \ldots, N$, where $L_{n}$ are areas of the essential values of $C_{n}^{*}$. The preliminary numerical experiments carried out have shown that a priori information about the location and boundaries of the contaminated plume is important in determining the $\Omega$ area. Location of the points $\left(x_{i}, y_{i}\right)$ on the pollution area boundary permits to narrow significantly the $\Omega$ area. The measuring data application in the points of maximal concentration leads to the better conditionality of the problem being solved of the $Q_{S}$. definition. Choosing $\left(x_{i}, y_{i}\right) \in \Omega$, $i=1, \ldots, M, M$ of the systems for various coordinates of the pollution source can be built. The best assessment of $Q_{S}$ will correspond to the true condition of the source. For the condition $\left(x_{i}, y_{i}\right)=\left(x_{0}, y_{0}\right)$ the values $Q_{S}^{n} \approx Q_{S}, n=1, \ldots, N$. The values of $Q_{S}$ are found from the system (10) by means of the filtration method [11], well-proven in the solution of oceanographic problems [12]. In case of the overdetermined system (10) and errors in the measuring of $C_{n}$, the measuring data filtration taking in account all the information concentrated in $N$ equations is necessary. As a result of this procedure, the equations of the new system are sorted by rank and uninformative equations are removed. Eventually, in the first equation of the system the equation with the best conditionality appears. By means of this equation the value of $Q_{S}$ is found

The results of numerical experiments. Numerical experiments were carried out applying the model of the work [1] to the Azov Sea. To test the algorithm of the source power identification, the calculation of the model current field under the influence of constant wind of the northeastern direction at a speed of $10 \mathrm{~m} / \mathrm{s}$ was performed. As a result of simulation the spatial distribution of the coefficients $A_{H}$ and $K$ was also obtained. The velocity fields and turbulent diffusion coefficients were used as input data in the integration of passive admixture transport model for a period of 5 days. 


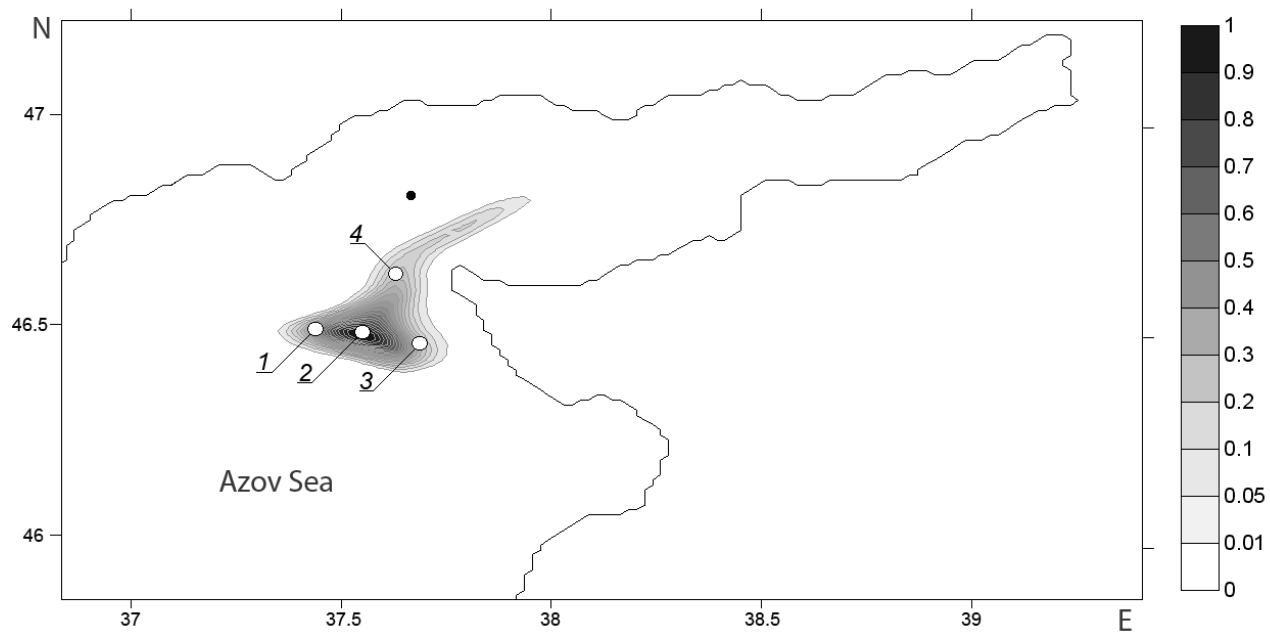

Fig. 1. Location of the instant point source, normed concentration field and measuring points

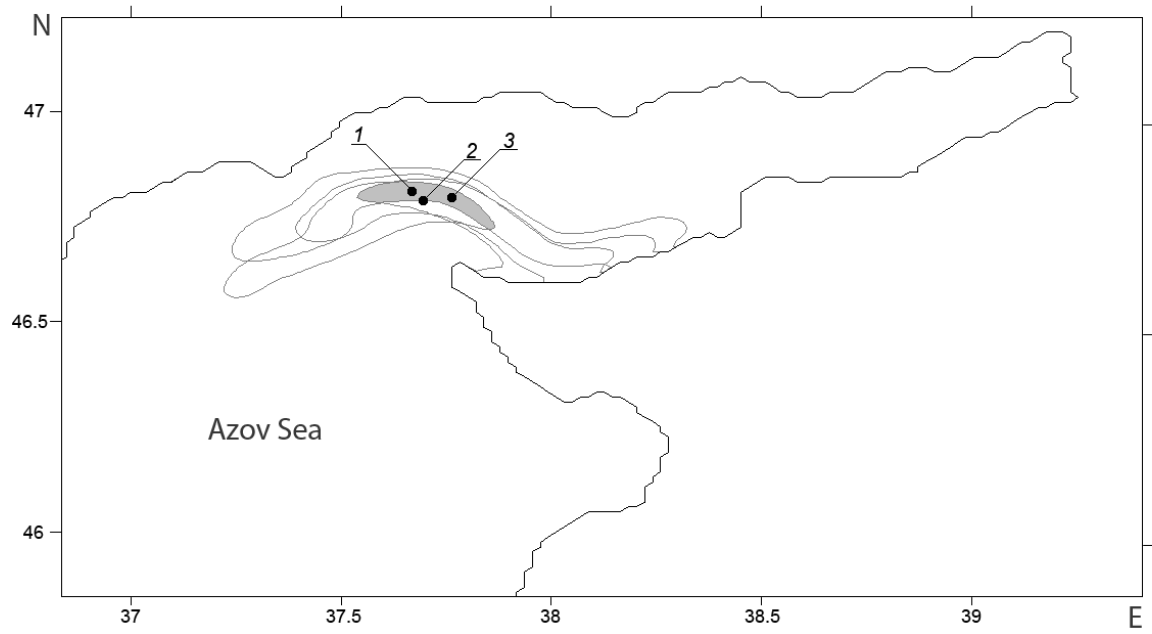

Fig. 2. Solution of the adjoint problems, $\Omega$ area and location of the pollution sources

Model concentration field was calculated when $Q_{S}=1$, and the calculation results were normalized to the maximum value. In Fig. 1 the true location of the instant point source is indicated by a black dot. Except the model concentration field, this figure shows four measuring points $(N=4)$. The result of integration of the four adjoint problems (6) $-(8)$ is demonstrated in Fig. 2. The $\Omega$ area corresponding to these adjoint problems is colored grey. From this figure it can be clearly seen that the true source location, marked by 1 , belongs to the $\Omega$ area. For this point the solution of the four equations of the system (10) has the following values: $Q_{S}^{1}=1.024, Q_{S}^{2}=0.9882, Q_{S}^{3}=0.9581, Q_{S}^{4}=1.2446$; for the point $2-$ $Q_{S}^{1}=0.8863, Q_{S}^{2}=2.2692, Q_{S}^{3}=1.3714, Q_{S}^{4}=21.1078$; for the point $3-$ 
$Q_{S}^{1}=2.5234, Q_{S}^{2}=1.1829, Q_{S}^{3}=0.4601, Q_{S}^{4}=1.2467$. The point 1 is the true location of the pollution source, as the values in this point are $Q_{S}^{i} \approx 1$. The values of $Q_{S}^{i}$ in the other points are increasingly different from each other, so are not considered. From the overdetermined system (10) for the point $l$ on the basis of the filtration method, $Q_{S}=1.0122$ is found.

Conclusion. The numerical experiments showed that the result of the pollution source identification parameters to a great degree depend on location of the measuring points. The most accurate reproduction of the true value of the power of the pollution source is obtained in the case where measurements are made in the area of maximum concentration field values, which leads to a better conditionality of the problem being solved. Application of the filtration method in solving the overdetermined system permits to obtain the solution with all the incoming data taken into account. In general, the performed numerical experiments show that the algorithm for the identification of pollution power source is reliable. The results can be used to solve various problems of ecological orientation in the study of the impact of anthropogenic pollution sources in the waters of the Azov and Black Seas.

Acknowledgements. The work was carried out within the framework the state order No. 0827-2014-0010 "Complex Interdisciplinary Studies of Oceanographic Processes Determining the Functioning and Evolution of the Black and Azov Sea Ecosystem on the Basis of Modern Methods of Control of the Marine Environment and Gridtehnology".

\section{REFERENCES}

1. Ivanov, V.A. and Fomin, V.V., 2008. Matematicheskoe Modelirovanie Dinamicheskikh Protsessov $v$ Zone More-Susha [Mathematical Modeling of the Dynamic Processes in the Zone Sea-Land]. Sevastopol: ECOSI-Gidrofizika, 363 p. (in Russian).

2. Marchuk, G.I. and Penenko, V.V., 1978. Application of Optimization Methods to the Problem of Mathematical Simulation of Atmospheric Processes and Environment. In: G. I. Marchuk, ed., 1978. Modeling and Optimization of Complex Systems, Proc. of the IFIP-TC7 Working Conf. New York: Springer, pp. 240-252.

3. Kochergin, S.V. and Kochergin, V.S., 2010. Ispol'zovanie Variatsionnykh Printsipov i Resheniya Sopryazhennoy Zadachi pri Identifikatsii Vkhodnykh Parametrov Modeli Perenosa Passivnoy Primesi [Using of Variational Principles and Adjoint Problem Decision during Identification of Input Parameters of Passive Impurity Transport Model]. In: Ekologicheskaya Bezopasnost' Pribrezhnoy $i$ Shel'fovoy zon $i$ Kompleksnoe Ispol'zovanie Resursov Shel'fa [Ecological Safety of Coastal and Shelf Zones and Complex Use of Shelf Resources]. Sevastopol: MGI NANU. Iss. 22, pp. 240-244 (in Russian).

4. Penenko, V.V., 1981. Metody Chislennogo Modelirovaniya Atmosfernykh Protsessov [Numerical Simulation Methods of the Atmospheric Processes]. Leningrad: Gidrometeoizdat, 350 p. (in Russian).

5. Agoshkov, V.I., Parmuzin, E.I. and Shutyaev, V.P., 2013. Observational Data Assimilation in the Problem of Black Sea Circulation and Sensitivity Analysis of its Solution. Izvestiya. Atmospheric and Oceanic Physics, [e-journal] 49(6), pp. 592-602. doi:10.1134/S0001433813060029 
6. Shutyaev, V.P., Le Dimet, F.-X., Agoshkov, V.I. and Parmuzin, E.I., 2015. Sensitivity of Functionals in Problems of Variational Assimilation of Observational Data. Izvestiya. Atmospheric and Oceanic Physics, [e-journal] 51(3), pp. 342-350. doi:10.1134/S0001433815030111

7. Ruabtzev, Yu.N. and Shapiro, N.B., 2009. Opredelenie Nachal'nogo Polozheniya Obnaruzhennykh v Otkrytoy Chasti Morya Poverkhnostnykh Linz Ponizhennoy Solenosti Primesi [Determination of the Initial Position Discovered in Open Part of Sea Lenses of Small Salinity]. In: Ekologicheskaya Bezopasnost' Pribrezhnoy $i$ Shel'fovoy Zon $i$ Kompleksnoe Ispol'zovanie Resursov Shel'fa [Ecological Safety of Coastal and Shelf Zones and Complex Use of Shelf Resources]. Sevastopol: MGI NANU. Iss. 18, pp. 141-157 (in Russian).

8. Kochergin, V.S. and Kochergin, S.V., 2015. Identification of a Pollution Source Power in the Kazantip Bay Applying the Variation Algorithm. Physical Oceanography, [e-journal] (2), pp. 79-88. doi:10.22449/1573-160X-2015-2-69-76

9. Marchuk, G.I., 1982. Matematicheskoe Modelirovanie v Probleme Okruzhayushchey Sredy [Mathematical Modeling in Environmental Problem]. Moscow: Nauka, 320 p. (in Russian).

10. Kochergin, V.S., 2011. Opredelenie Polya Kontsentratsii Passivnoy Primesi po Nachal'nym Dannym na Osnove Resheniya Sopryazhennykh Zadach [Determining the Concentration Field with Use the Data Measurements Based on Solving of Adjoint Problems]. In: Ekologicheskaya Bezopasnost' Pribrezhnoy i Shel'fovoy Zon $i$ Kompleksnoe Ispol'zovanie Resursov Shel'fa [Ecological Safety of Coastal and Shelf Zones and Complex Use of Shelf Resources]. Sevastopol: MGI NANU. Iss. 25, vol. 2, pp. 357-370 (in Russian).

11. Strakhov, V.N., 1991. Metod Fil'tratsii Sistem Lineynykh Algebraicheskikh UravneniyOsnova dlya Resheniya Lineynykh Zadach Gravimetrii i Magnitometrii [The Method of Filtering Systems of Linear Algebraic Equations - the Basis for the Solution of Linear Problems of Gravity and Magnetic Measurements]. Doklady AN SSSR, 320(3), pp. 595-599 (in Russian).

12. Eremeev, V.N., Kochergin, V.P., Kochergin, S.V. and Sklyar, S.N., 2002. Matematicheskoe Modelirovanie Gidrodinamiki Glubokovodnykh Basseynov [Mathematical Modeling of Hydrodynamics of Deep Water Basins]. Sevastopol: ECOSI-Gidrofizika, 238 p. (in Russian). 